\title{
Pericardial Effusion and Cardiac Tamponade Following Percutaneously Inserted Central Line Insertion in an Extremely Low-birth-weight Baby: Case Report and Successful Management
}

\author{
Avinash V. Desai, Abnish Kumar, Praful Shanbhag, Forum Shah \\ Department of Neonatology, Nowrosjee Wadia Maternity Hospital, Acharya Donde Marg, Mumbai, Maharashtra, India
}

\section{Abstract}

Pericardial effusion and cardiac tamponade are rare complications of percutaneously inserted central lines (PICLs), in extremely low-birth-weight babies. This particular complication carries a high degree of mortality, if not suspected and diagnosed. Bedside echocardiography proves not only diagnostic but also can be lifesaving in these conditions. Here, we wish to report such a baby who suddenly deteriorated and showed cardiovascular instability 2 days after the insertion of PICL. Immediate bedside echocardiography helped pick up the effusion which was drained using a subxiphoid percutaneous approach.

Key words: Extremely low-birth-weight baby, pericardial effusion, pericardiocentesis, percutaneously inserted central lines

\section{INTRODUCTION}

Percutaneously inserted central lines (PICLs) are routinely used in Neonatal Intensive Care Units for even the tiniest of babies, to provide medications and parenteral nutrition. This procedure has been associated with many complications, of which pericardial effusion (PCE) and cardiac tamponade are rare.$^{[1]}$ The incidence of this complication is 1.8/1000 lines and case fatality rate of $0.7 / 1000$ lines. ${ }^{[2]}$ Others have reported an incidence in the range of $0.76 \%-1.8 \%{ }^{[3]}$ The mortality rate may vary from $45 \%$ to $67 \%{ }^{[4]}$ Hence, even though rare, this particular complication carries a high degree of mortality and morbidity. The purpose of this report is to sensitize the clinicians to this fatal complication; to have a high degree of suspicion for this, especially in a baby with PICL line who suddenly deteriorates or has cardiopulmonary instability. In addition, emphasized here is how a bedside basic echocardiography can be diagnostic and lifesaving for these babies.

\section{Case Report}

A male preterm $980 \mathrm{~g}$ by birth weight was born to 25 -year-old primigravida with 28 weeks of gestation. The baby was

\begin{tabular}{|l|l|}
\hline \multicolumn{2}{|c|}{ Access this article online } \\
\hline Quick Response Code: & Website: \\
\hline & www.ijccm.org \\
\hline & \\
\hline
\end{tabular}

delivered with a cesarean section for the indication of fetal distress. In view of respiratory distress, the baby received single dose of natural bovine surfactant within half an hour of birth and was ventilated with nasal continuous positive airway pressure. A PICL (Vygon, Germany) was inserted electively on the $5^{\text {th }}$ day of life through the right saphenous vein. The chest $\mathrm{X}$-ray confirmed the position of the catheter tip at the junction of inferior vena cava and right atrium just above the diaphragm. On the $7^{\text {th }}$ day of life, the baby suddenly deteriorated in the form of desaturations, tachycardia, and hypotension. On examination, the neonate appeared cyanosed, with saturations of $85 \%$ and delayed capillary refill time. On auscultation, the heart sounds were feeble and blood pressure showed a systolic reading of $30 \mathrm{~mm}$ mercury. The baby was therefore immediately intubated and was put on

Address for correspondence: Dr. Avinash V. Desai, Manas Clinic, Office No. 4, Shivam Building Gopi Tank Road, Matunga West, Mumbai - 400 016, Maharashtra, India. E-mail: dravdesai@gmail.com

This is an open access article distributed under the terms of the Creative Commons Attribution-NonCommercial-ShareAlike 3.0 License, which allows others to remix, tweak, and build upon the work non-commercially, as long as the author is credited and the new creations are licensed under the identical terms.

For reprints contact: reprints@medknow.com

How to cite this article: Desai AV, Kumar A, Shanbhag P, Shah F. Pericardial effusion and cardiac tamponade following percutaneously inserted central line insertion in an extremely low-birth-weight baby: Case report and successful management. Indian J Crit Care Med 2017;21:57-9. 
mechanical ventilation with pressure control mode and $100 \%$ oxygen. Systemic hypotension was corrected with inotropes. In view of this sudden deterioration, a chest roentgenogram was called for, which showed marked cardiomegaly and a cardiothoracic ratio of 0.68 [Figure 1]. In view of the above findings, a two-dimensional echocardiogram was performed, which showed a massive PCE [Figure 2]. There was a diastolic collapse of the free wall of the right atrium, indicating cardiac tamponade. Pericardiocentesis was immediately performed, and $9 \mathrm{ml}$ of yellowish fluid was aspirated through a subxiphoid percutaneous approach. Subsequently, the skin color of the neonate improved rapidly, his vital signs gradually returned to normal, and his oxygen requirement decreased from $90 \%$ to $30 \%$. Echocardiography done later showed increased contractility with resolution of the PCE [Figure 3]. The PICL line was immediately withdrawn. Inotropic support was gradually reduced and omitted after $24 \mathrm{~h}$; the pressure support for the baby was also gradually reduced and the baby was weaned off the ventilator the next day. Biochemical analysis of the obtained pericardial fluid revealed a glucose concentration of $1215 \mathrm{mg} / \mathrm{dl}$ and total protein of $0.1 \mathrm{~g} / \mathrm{dl}$. There were $100 \mathrm{red}$ blood cells $/ \mathrm{mm}^{3}$ and 50 white blood cells $/ \mathrm{mm}^{3}$. The aspirated fluid was suggestive of total parenteral nutrition infusate. There was no further accumulation of fluid, and a follow-up echocardiogram after a week was normal. The baby was started on trophic feeds 3 days after pericardiocentesis. The patient was subsequently discharged, and a chest roentgenogram done before discharge showed a normal cardiothoracic ratio.

\section{Discussion}

With advances in neonatal care, survival among the extremely low-birth-weight babies has improved significantly. Part of these advances involves total parenteral nutrition and fluid management. PICL lines have therefore become an integral part of these strategies. The need for placing these lines for a longer duration has become a necessity. In spite of the correct position of central lines, clinicians have encountered PCE as a complication. ${ }^{[5]}$ Although positioning of the catheter tip at the level of T8-9 is acceptable on X-ray, it has been suggested that the catheter tip is not only outside the cardiac silhouette but also the intrapericardial portion of the great vessels $(1 \mathrm{~cm}$ outside the cardiac silhouette in preterm and $2 \mathrm{~cm}$ in term neonates). Clinical presentations may vary from sudden cardiac collapse to unexplained cardiovascular instability. The cause for such effusions is not clear, but various theories have been suggested based on clinical findings. ${ }^{[6]}$ The authors have attributed the damage to the termination site and the angle at which the catheter lies within the heart, repeated contact of the catheter tip with the cardiac wall may result in endothelial injury and thrombus formation, and this endothelial injury and adherence of the tip to the cardiac wall due to the thrombus may eventually lead to diffusion of fluid in the pericardial space. There are case reports of cardiac tamponade even in

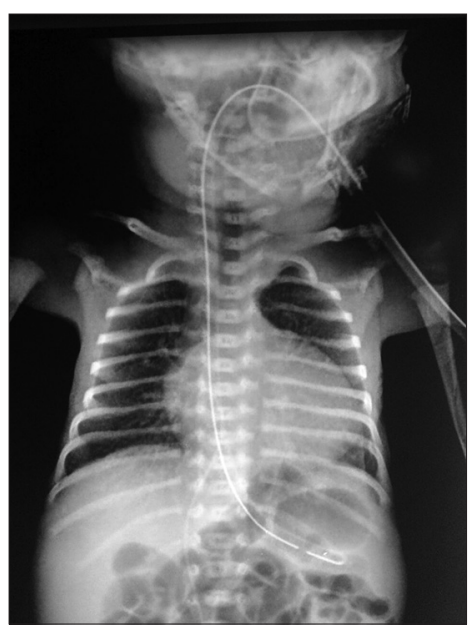

Figure 1: X-ray showing percutaneously inserted central lines in situ and pericardial effusion.

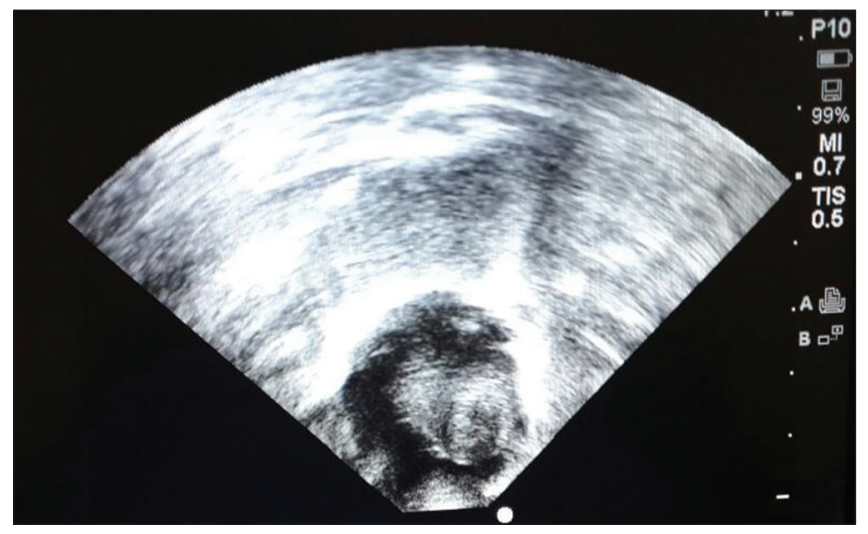

Figure 2: Echocardiography showing evidence of pericardial effusion.

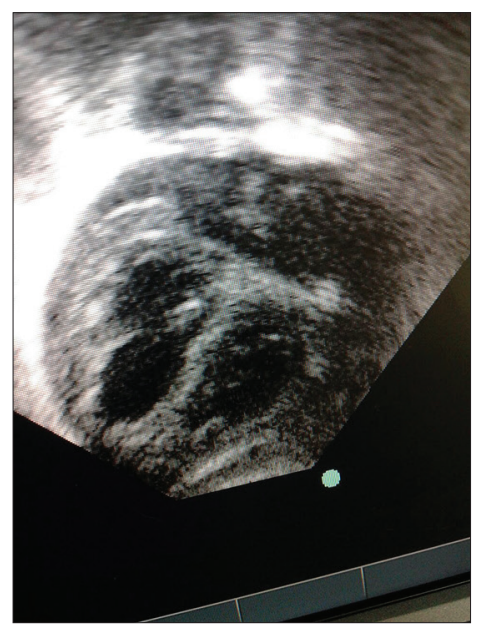

Figure 3: Post aspiration echocardiogram showing resolution of the effusion.

babies with correctly positioned catheter tip. Hyperosmolar infusates and subsequent endothelial damage and necrosis may be the causes of effusion in these patients. This complication can present at any time during which the catheter is in situ. The median time reported was 3.2 days from insertion, range 
0.4 days to 13.5 days. ${ }^{[7]}$ An increase in the cardiothoracic ratio along with cardiovascular instability should alert the clinician to this serious complication. A bedside echocardiography is not only diagnostic but also lifesaving as we demonstrated in our case. Bedside echocardiography should become an integral part of training and assessment in tertiary neonatal care units. ${ }^{[8]}$ Subxiphoid percutaneous approach is safe and effective in treating the tamponade as we demonstrated in our case.

\section{Acknowledgments}

We would like to thank our Medical Directors Dr. Amdekar and Dr. Jassawalla, CEO Dr. M. Bodhanwala, and our HOD Dr. Sudha Rao for allowing us to publish the article.

\section{Financial support and sponsorship}

Nil.

\section{Conflicts of interest}

There are no conflicts of interest.

\section{References}

1. Menon G. Neonatal long lines. Arch Dis Child Fetal Neonatal Ed 2003;88:F260-2.

2. Beardsall K, White DK, Pinto EM, Kelsall AW. Pericardial effusion and cardiac tamponade as complications of neonatal long lines: Are they really a problem? Arch Dis Child Fetal Neonatal Ed 2003;88:F292-5.

3. Ramasethu J. Complications of vascular catheters in the neonatal Intensive Care Unit. Clin Perinatol 2008;35:199-222, x.

4. Nowlen TT, Rosenthal GL, Johnson GL, Tom DJ, Vargo TA. Pericardial effusion and tamponade in infants with central catheters. Pediatrics 2002;110(1 Pt 1):137-42.

5. Onal EE, Saygili A, Koç E, Türkyilmaz C, Okumus N, Atalay Y. Cardiac tamponade in a newborn because of umbilical venous catheterization: Is correct position safe? Paediatr Anaesth 2004;14:953-6.

6. Arya SO, Hiremath GM, Okonkwo KC, Pettersen MD. Central venous catheter-associated pericardial tamponade in a 6-day old: A case report. Int J Pediatr 2009;2009:910208.

7. Jouvencel P, Tourneux P, Pérez T, Sauret A, Nelson JR, Brissaud O, et al. Central catheters and pericardial effusion: Results of a multicentric retrospective study. Arch Pediatr 2005;12:1456-61.

8. Katumba-Lunyenya JL. Neonatal/infant echocardiography by the non-cardiologist: A personal practice, past, present, and future. Arch Dis Child Fetal Neonatal Ed 2002;86:F55-7. 